\title{
Optimal incentive mechanism for dual referral based on the analytic hierarchy process
}

\author{
Guanghe Lei
}

\section{Abstract}

Objective: The optimal incentive mechanism for dual referral is discussed to provide a decision-making foundation for the implementation of a dual referral incentive mechanism.

Methods: We established a multi-hierarchy evaluation model for a dual referral incentive mechanism by analyzing the main schemes and measures used to stimulate dual referral. The weight values of every scheme or measure were determined and consistency tests were carried out using expert judgement methods and an analytic hierarchy process.

Results: The weight values of patients, community physicians, and hospital physicians as the incentive objects were $0.2583,0.1047$, and 0.6370 , respectively, and the weight values of medical insurance-based reward and punishment, community medical center construction, referral platform, and publicity and communication as incentive schemes were $0.4950,0.3103,0.1164$, and 0.0783 , respectively.

Conclusion: The main incentive object in the implementation of a dual referral is the hospital physician, followed by the patient. The most workable incentive scheme is "medical insurancebased reward and punishment," followed by "community medical center construction."

Keywords: Dual referral, Incentive mechanism, Analytic hierarchy process, Incentive object, Incentive scheme

\section{Introduction}

A two-way referral system not only helps to improve the utilization efficiency of limited medical resources, but is also convenient for patients seeking medical services, and thus saves medical costs. "The Decision of the CPC Central Committee and State Council on Health Reform and Development" ([1997] No. 3) [1] in 1997 made it clear that community health services should be included in employee medical insurance, and it is thus necessary to establish a two-way referral system. Moreover, the Ministry of Health has repeatedly issued documents requiring nationwide implementation; however, the effect thus far has been unsatisfactory. The implementation of initial diagnostic mechanisms by grassroots hospitals has not been fully embraced by residents; however, the upward and downward referral rates are extremely limited [2,3]. Current research on two-way referral mainly focuses on the reasons for these problems, and proposes some countermeasures. Chen [4] and Chen et al. [5] suggested that the reasons were inadequate policy guidance, conflicts of
CORRESPONDING AUTHOR:

Guanghe Lei,

School of Humanities and Management, Guangdong Medical College, Dongguan, China 523808

E-mail: 258002183@qq.com

Funding: Funded by the Guangdong Province Disciplinary Cooperative Project of Philosophy and Social Science under the Twelfth Five-year Plan [GD11XGL19], 2011

Received 25 September 2013; Accepted 21 December 2013 
interest between medical institutions, lack of professional skills amongst community general practitioners, defective functions of community medical institutions, an imperfect two-way referral mechanism, and lack of an effective public information platform. Yang et al. [6] and Xiong et al. [7] proposed to establish a standardized two-way referral policy and an effective referral procedure, strengthen the publicity for two-way referral, promote the primary health care function of community health service centers, distribute the economic benefits reasonably, and establish a sensible and effective incentive and accountability mechanism for twoway referral. The countermeasures have an incentive role in implementing the two-way referral system; however, the priority of each policy is not clear and it is difficult to assign implementation priorities because the incentive structure and influence of each policy have not been distinguished. The policy guidance is therefore not sufficient. If the optimal incentive mechanism can be selected, it will provide significant help for policy guidance. In this study, we used an analytic hierarchy process (AHP) and expert judgment to analyze and judge the optimal incentive mechanism of twoway referral.

\section{Methods}

The AHP was formally proposed by an American expert in operations research (TL Saaty) in the mid-1970s. The AHP applies a hierarchy to a complex decision-making system. The qualitative criteria for analysis and decision-making are provided by comparing the importance of every two correlated factors, layer-by-layer. This method is especially suitable for conditions in which it is difficult to measure the decision-making outcome accurately.

First, the correlated factors are decomposed into several layers from the top down according to different attributes, based on an in-depth analysis of practical problems. Factors in the same layer are subordinate to or have an impact on those in the upper layer, and dominate or are influenced by factors in the lower layer. The topmost layer is the object layer, which consists of only one factor, and the lowest layer is the action or object hierarchy. There can be one or several layers between the topmost and lowest layers (usually the criteria or index layers).

Starting from the second layer of the hierarchical model, factors in the same layer, which are subordinate to or have an influence on each factor in the upper layer, form the paired comparison matrix by the paired comparison method and 1 9 comparison scale down to the lowest layer. The method of calculation is shown in Table 1.

Because the incentive of two-way referral involves a specialized field, the method of expert judgment was adopted. Using a questionnaire survey, 10 experts specialized in two-way referral were invited to compare and assign weights to the factors in each layer. The average age of the experts was 50 years, and the average working life was 27 years. All the experts had master's degrees or above, worked in hospitals, social security agencies, medical colleges, or community health institutions. The relevant fields were health care management, management, public management, and preventive medicine. The experts mainly performed research in the fields of sanitation management, public policies, and public sanitation, and actively cooperated with the investigation.

Table 1. Value of judgment matrix in the AHP

\begin{tabular}{ll}
\hline Fraction & Connotation \\
\hline 1 & Factors $\mathrm{A}_{\mathrm{i}}$ and $\mathrm{A}_{\mathrm{j}}$ are equally important by the paired comparison method. \\
3 & Factor $\mathrm{A}_{\mathrm{i}}$ is slightly more important than $\mathrm{A}_{\mathrm{j}}$ by the paired comparison. \\
5 & Factor $\mathrm{A}_{\mathrm{i}}$ is clearly more important than $\mathrm{A}_{\mathrm{j}}$ by the paired comparison. \\
7 & Factor $\mathrm{A}_{\mathrm{i}}$ is highly more important than $\mathrm{A}_{\mathrm{j}}$ by the paired comparison. \\
9 & Factor $\mathrm{A}_{\mathrm{i}}$ is extremely more important than $\mathrm{A}_{\mathrm{j}}$ by the paired comparison. \\
$2,4,6,8$ & The median between the two adjacent judgment matrices. \\
Reciprocal & Value $\mathrm{a}_{\mathrm{ij}}$ can be obtained by comparing factor $\mathrm{A}_{\mathrm{i}}$ to $\mathrm{A}_{\mathrm{j}}$ and value $\mathrm{a}_{\mathrm{ji}}=1 / \mathrm{a}_{\mathrm{ij}}$ by comparing factor $\mathrm{A}_{\mathrm{j}}$ to $\mathrm{A}_{\mathrm{i}}$. \\
\hline
\end{tabular}


Additionally, the weight vector was calculated and a consistency test was performed. For each matrix obtained by paired comparison, the maximum eigenvalues and the corresponding eigenvectors were calculated, and a consistency test was performed using a consistency index. If the test was passed, the eigenvectors (after normalization) were the weight vectors; if not, the paired comparison matrix was reconstructed.

Finally, the compound weight vector was calculated. There was no need to verify the consistency again because the test had been performed for each layer.

\section{Results}

Hierarchy structure construction of the optimal incentive mechanism for two-way referral

The optimal incentive mechanism for two-way referral was determined by literature analysis and investigative research (Fig. 1).
The optimal incentive mechanism for two-way referral contained three aspects (encouraging patients, community physicians, and hospital physicians). Each mechanism involved four schemes, with 12 measures in total. The specific contents are described below.

\section{Implementation of the incentive mechanism for medical insurance reimbursement}

Encouraging patients: For example, the amount reimbursed by the medical insurance should be increased to relieve outpatient charges for referral patients. Conversely, charges cannot be reimbursed by medical insurance for patients who go directly to the hospital without referral. Moreover, the difference in reimbursement amount at different medical institutions, such as community health care institutions and hospitals, should be expanded, and the difference in charges between different medical institutions should be widened.

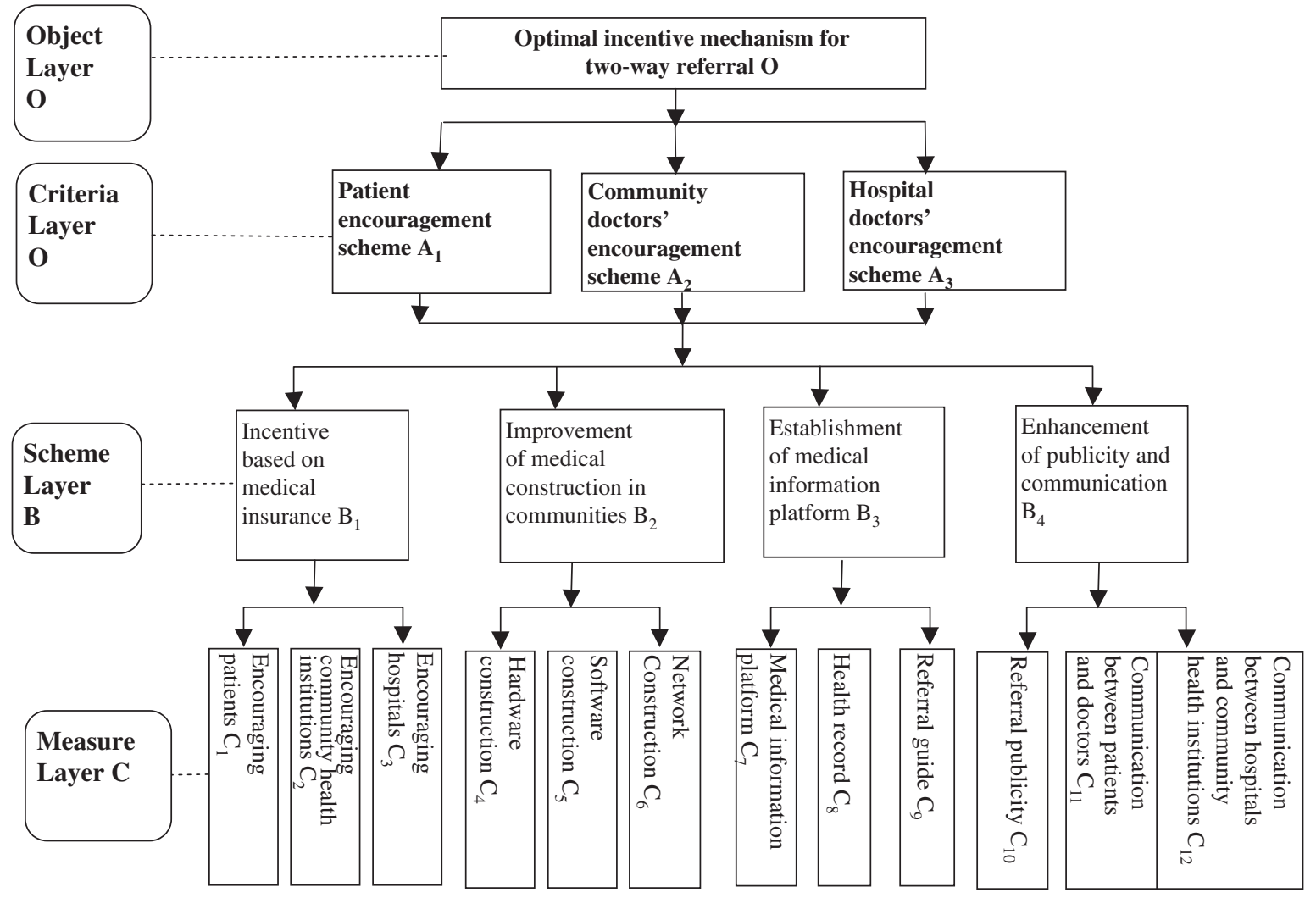

Fig. 1. Hierarchies of optimal incentive mechanism for two-way referral. 
Encouraging community health care institutions: Community physicians who implement referrals will be awarded the saved charges of the medical insurance after referrals. In contrast, physicians who do not implement referrals will be penalized appropriately. In addition, more construction funds will be invested to the community health institutions that do well in terms of referrals.

Encouraging hospitals: Hospital physicians who implement referrals will be awarded the saved charges of the medical insurance after referrals. Conversely, those who do not implement the referrals will be penalized appropriately. In addition, gross expenditure control was implemented for medical insurance reimbursement.

\section{Improvement of hardware and software in community health institutions to reduce resistance to two-way referrals}

Hardware: Inspection of equipment in community health service centers should be improved.

Software: The professional skills of general practitioners in community health institutions should be improved to promote the trust of patients and hospital physicians. For example, access regulations for general physicians should be strictly controlled to guarantee the quality of physicians in community health institution. Diversified training should be adopted to promote the professional development of community physicians. Diverse financing mechanisms on the part of financial departments, institution, and individuals should be set up to promote the training of the community physicians. Finally, the professional identities of and service quality provided by community health workers could be improved by promoting the welfare and income of the workers.

Network construction: Building a network of community health care centers can provide a convenient means of providing common disease treatments for residents.

\section{Building of the medical information sharing platform to facilitate two-way referrals \\ Medical information platform: The medical informa-} tion platform should be built to promote information sharing among community institutions, hospitals, and IESS.
Health records: The health record database of the residents should be designed to promote information sharing between residents and physicians. In addition, constructing an online interactive platform will enable residents to make an appointment at the time of the initial diagnosis and rehabilitation consultation via the community health institution's website.

Referral guide: A specific guide for two-way referrals, including information on referral conditions, procedures, and protocols, should be developed, and the supervisory mechanism for two-way referrals needs to be improved.

\section{Enhancement of publicity and communication to} promote the influence of community health service center

Referral publicity: It is essential to publicize the advantages of the two-way referral system in the form of bulletin boards and banners.

Communication between patients and physicians: It is necessary to improve health education and promote physician-patient communication. For example, multifunctional service projects, such as health consultations, health care of women and children, mental consultations, and rehabilitation guidance, should be added. It is also necessary to build family physicians or health consultant teams dominated by general practitioners and to implement family physician or health consultation services based on a contract system. These measured would increase the trust of residents towards community general practitioners.

\section{Communication between hospitals and community} health institutions: It is necessary to promote communication between hospitals and community health institutions in order to increase mutual trust between hospitals and community health institutions. For example, communication of information regarding the conditions and rehabilitation states of two-way referral patients between community physicians and hospital physicians should be maintained. In addition, medical experts could be invited to give health lectures in community health institutions. Hospital physicians could also be invited to do part-time work or accept temporary posts in community 
health institutions, while community physicians could be sent to hospitals for education and training.

\section{Hierarchy analysis}

The expert judgment method, 1-9 comparison scale, and relative weights were used to analyze the incentive measures. The experts assigned weights to each index by paired comparison. The integers or their reciprocals with a minimum deviation were chosen as the final results of the paired comparison. Thus, the comparison matrix can be constructed.

\section{Judgment matrices}

The O-A judement matrix is shown in Table 2. The A-B and B-C matrices are shown in Tables 3-5 and 6-9, respectively.

\section{Total ranking of hierarchies}

The total ranking of hierarchies is shown in Table 10.

\section{Discussion}

From the perspective of the incentive objects, encouraging hospital physicians occupied the most important position, followed by encouraging patients and encouraging community physicians. There are two possible reasons for this. Physicians always play a dominant role in the physician-patient relationship. Patients can only follow the physicians' arrangements regarding upward or downward referral. The inadequacies of software and hardware conditions in community health institutions means that there will always be an upward referral for patients whose conditions are beyond the capabilities of the community physicians. In contrast, hospital physicians have almost complete decision-making power regarding whether or not to allow the downward referral of patients.

From the perspective of incentive schemes, it is most effective to implement incentives based on medical insurance, followed by promoting community health institution

Table 2. O-A judgment matrix

\begin{tabular}{llllll}
\hline O-A & $\mathrm{A}_{1}$ & $\mathrm{~A}_{2}$ & $\mathrm{~A}_{3}$ & Eigenvector & Weight $\mathrm{W}_{\mathrm{a}}$ (after normalization) \\
\hline Encouraging patients $\mathrm{A}_{1}$ & 1 & 3 & 0.3333 & 0.3715 & 0.2583 \\
Encouraging community physicians $\mathrm{A}_{2}$ & 0.3333 & 1 & 0.2 & 0.1506 & 0.1047 \\
Encouraging hospital physicians $\mathrm{A}_{3}$ & 3 & 5 & 1 & 0.9161 & 0.6370 \\
\hline
\end{tabular}

Matlab (7.0) was used to calculate the matrix, $\lambda_{\max }=3.0385$, because $\mathrm{CI}=\lambda_{\max }-n / n-1$ and $n=3, \mathrm{CI}=0.01925, \mathrm{RI}=0.58, \mathrm{CR}=\mathrm{CI} / \mathrm{RI}=0.0332<0.10$, and the consistency test was passed. After normalization, the weights of $\mathrm{A}_{1}, \mathrm{~A}_{2}$, and $\mathrm{A}_{3}$ were $0.2583,0.1047$, and 0.6370 , respectively, with respect to the target. This shows that the experts considered that encouraging hospital physicians was the most important aspect of the optimal incentive mechanism, followed by encouraging patients, while encouraging community physicians was the least important.

Table 3. A - B judgment matrix

\begin{tabular}{lllllll}
\hline $\mathrm{A}_{1}-\mathrm{B}$ & $\mathrm{B}_{1}$ & $\mathrm{~B}_{2}$ & $\mathrm{~B}_{3}$ & $\mathrm{~B}_{4}$ & Eigenvectors & Weight $\mathrm{W}_{\mathrm{b}}$ (after normalization) \\
\hline Incentive by medical insurance $\mathrm{B}_{1}$ & 1 & 3 & 5 & 7 & 0.8880 & 0.5650 \\
Community health institution construction $\mathrm{B}_{2}$ & 0.3333 & 1 & 3 & 5 & 0.4121 & 0.2622 \\
Referral platform $\mathrm{B}_{3}$ & 0.2 & 0.3333 & 1 & 3 & 0.1847 & 0.1175 \\
Publicity and communication $\mathrm{B}_{4}$ & 0.1429 & 0.2 & 0.3333 & 1 & 0.0869 & 0.0553 \\
\hline
\end{tabular}

$\lambda_{\max }=4.1170, \mathrm{CI}=0.039, \mathrm{RI}=0.90$, and $\mathrm{CR}=\mathrm{CI} / \mathrm{RI}=0.043<0.10$. Thus, the consistency test was passed. The weights show that an incentive based on medical insurance was the most important aspect of an optimal incentive mechanism, followed by promotion of software and hardware improvements in primary medical service centers, such as community health institution, construction of a referral platform, and the promotion of publicity and communication. 
Table 4. $\mathrm{A}_{2}-\mathrm{B}$ judgment matrix

\begin{tabular}{lllllll}
\hline $\mathrm{A}_{2}-\mathrm{B}$ & $\mathrm{B}_{1}$ & $\mathrm{~B}_{2}$ & $\mathrm{~B}_{3}$ & $\mathrm{~B}_{4}$ & Eigenvectors & Weight $\mathrm{W}_{\mathrm{b}}$ (after normalization) \\
\hline Incentive by medical insurance $\mathrm{B}_{1}$ & 1 & 0.1429 & 0.3333 & 0.2 & -0.0838 & 0.0531 \\
Community health institution construction $\mathrm{B}_{2}$ & 7 & 1 & 5 & 3 & -0.8651 & 0.5485 \\
Referral platform $\mathrm{B}_{3}$ & 3 & 0.2 & 1 & 0.2 & -0.1605 & 0.1018 \\
Publicity and communication $\mathrm{B}_{4}$ & 5 & 0.3333 & 5 & 1 & -0.4678 & 0.2966 \\
\hline
\end{tabular}

$\lambda_{\max }=4.2282, \mathrm{CI}=0.076$, and $\mathrm{RI}=0.90$, hence $\mathrm{CR}=\mathrm{CI} / \mathrm{RI}=0.0845<0.10$. The consistency test was passed. It can be seen from the weights that the most important aspect of an optimal incentive mechanism for community physicians was the promotion of software and hardware improvements in community health institutions, as well as network construction, followed by the promotion of publicity and communication, construction of a referral platform, and the implementation of incentives based on the medical insurance.

Table 5. A-B judgment matrix

\begin{tabular}{lllllll}
\hline $\mathrm{A}_{3}-\mathrm{B}$ & $\mathrm{B}_{1}$ & $\mathrm{~B}_{2}$ & $\mathrm{~B}_{3}$ & $\mathrm{~B}_{4}$ & Eigenvectors & Weight $\mathrm{W}_{\mathrm{b}}$ (after normalization) \\
\hline Incentive by medical insurance $\mathrm{B}_{1}$ & 1 & 2 & 5 & 9 & 0.8613 & 0.5392 \\
Community health institution construction $\mathrm{B}_{2}$ & 0.5 & 1 & 3 & 5 & 0.4643 & 0.2906 \\
Referral platform $\mathrm{B}_{3}$ & 0.2 & 0.3333 & 1 & 3 & 0.1892 & 0.1184 \\
Publicity and communication $\mathrm{B}_{4}$ & 0.1111 & 0.2 & 0.3333 & 1 & 0.0827 & 0.0518 \\
\hline
\end{tabular}

$\lambda_{\max }=4.0408, \mathrm{CI}=0.0136$, and $\mathrm{RI}=0.90$, hence $\mathrm{CR}=\mathrm{CI} / \mathrm{RI}=0.0151<0.10$. The consistency test was passed. It can be seen from the weights that implementing incentives based on medical insurance was the most effective aspect of an optimal incentive mechanism for physicians. The second most effective measure was promoting software and hardware improvements in primary medical service centers, such as community health institutions, making physicians feel secure about the service after downward referral to the community health institutions. The next most important measure was the construction of a referral platform and system, which facilitates two-way referral between hospitals and community health institutions. The least important factor was the promotion of publicity and communication.

Table 6. $B_{1}-\mathrm{C}$ judgment matrix

\begin{tabular}{llllll}
\hline $\mathrm{B}_{1}-\mathrm{C}$ & $\mathrm{C}_{1}$ & $\mathrm{C}_{2}$ & $\mathrm{C}_{3}$ & Eigenvectors & Weight $\mathrm{W}_{\mathrm{c}}$ (after normalization) \\
\hline Encouraging Patients $\mathrm{C}_{1}$ & 1 & 3 & 0.5 & -0.4629 & 0.3090 \\
Encouraging Community Health Institution $\mathrm{C}_{2}$ & 0.3333 & 1 & 0.2 & -0.1639 & 0.1094 \\
Encouraging Hospitals $\mathrm{C}_{3}$ & 2 & 5 & 1 & -0.8711 & 0.5815 \\
\hline
\end{tabular}

$\lambda_{\max }=3.0037, \mathrm{CI}=0.00185$, and $\mathrm{RI}=0.58$, hence $\mathrm{CR}=\mathrm{CI} / \mathrm{RI}=0.0032<0.10$. The consistency test was passed. It can be seen from the weights that encouraging hospital physicians was most effective when applying the medical insurance policy to implement the incentives for two-way referral, followed by encouraging patients and encouraging community physicians.

construction, building a referral platform, and promoting publicity and communication. There are several possible reasons for these priorities. As Marx said, material motives are hidden behind all human motives. Material incentive measures play the most important roles in all incentive schemes. One of the important reasons why hospital physicians and patients are reluctant to have downward referral to community health institutions is the relatively low level of clinical treatment. Hospital physicians worry that they will be influenced and involved because the patient's condition cannot be effectively treated after downward referral, while patients fear that their conditions will worsen or treatment will be delayed. These 
Table 7. $\mathrm{B}_{2}-\mathrm{C}$ judgment matrix

\begin{tabular}{llllll}
\hline $\mathrm{B}_{2}-\mathrm{C}$ & $\mathrm{C}_{4}$ & $\mathrm{C}_{5}$ & $\mathrm{C}_{6}$ & Eigenvectors & Weight $\mathrm{W}_{\mathrm{c}}$ (after normalization) \\
\hline Hardware Construction $\mathrm{C}_{4}$ & 1 & 0.3333 & 2 & -0.3287 & 0.2296 \\
Software Construction $\mathrm{C}_{5}$ & 3 & 1 & 5 & -0.9281 & 0.6483 \\
Network Construction $\mathrm{C}_{6}$ & 0.5 & 0.2 & 1 & -0.1747 & 0.1220 \\
\hline
\end{tabular}

$\lambda_{\max }=3.0037, \mathrm{CI}=0.00185$, and $\mathrm{RI}=0.58$, hence $\mathrm{CR}=\mathrm{CI} / \mathrm{RI}=0.0032<0.10$. The consistency test was passed. It can be seen that, when encouraging two-way referral by promoting community health institution construction, software construction should be promoted first, followed by hardware construction, and finally network construction.

Table $8 . B_{3}$-C judgment matrix

\begin{tabular}{llllll}
\hline $\mathrm{B}_{3}-\mathrm{C}$ & $\mathrm{C}_{7}$ & $\mathrm{C}_{8}$ & $\mathrm{C}_{9}$ & Eigenvectors & ${\text { Weight } \mathrm{W}_{\mathrm{c}} \text { (after normalization) }}^{\text {Medical information platform } \mathrm{C}_{7}}$ \\
Health record $\mathrm{C}_{8}$ & 1 & 3 & 0.5 & -0.4629 & 0.3090 \\
Referral guide $\mathrm{C}_{9}$ & 0.3333 & 1 & 0.2 & -0.1639 & 0.1094 \\
\hline
\end{tabular}

$\lambda_{\text {max }}=3.0037, \mathrm{CI}=0.00185$, and $\mathrm{RI}=0.58$, hence $\mathrm{CR}=\mathrm{CI} / \mathrm{RI}=0.00319<0.10$. The consistency test was passed. It can be seen that when encouraging two-way referral by constructing an information platform, the first consideration was to determine the referral guide, followed by constructing a good medical information sharing platform between community health service center and hospitals. Building the health record was least effective.

Table 9. $\mathrm{B}_{4}-\mathrm{C}$ judgment matrix

\begin{tabular}{llllll}
\hline $\mathrm{B}_{4}-\mathrm{C}$ & $\mathrm{C}_{10}$ & $\mathrm{C}_{11}$ & $\mathrm{C}_{12}$ & Eigenvectors & Weight $\mathrm{W}_{\mathrm{c}}$ (after normalization) \\
\hline Referral publicity $\mathrm{C}_{10}$ & 1 & 0.3333 & 0.1429 & 0.1226 & 0.0880 \\
Communication between physicians and patients $\mathrm{C}_{11}$ & 3 & 1 & 0.3333 & 0.3382 & 0.2426 \\
Communication between hospitals and communities $\mathrm{C}_{12}$ & 7 & 3 & 1 & 0.9331 & 0.6694 \\
\hline
\end{tabular}

$\lambda_{\max }=3.0071, \mathrm{CI}=0.00355$, and $\mathrm{RI}=0.58$, and hence $\mathrm{CR}=\mathrm{CI} / \mathrm{RI}=0.00612<0.10$. The consistency test was passed. The weights showed that, when encouraging two-way referral by promoting publicity and communication, priority should be given to the promotion of communication between hospitals and community health institutions, followed by communication between physicians and patients, and finally the promotion of publicity for two-way referral.

concerns can only be resolved by promoting the construction of community health institutions. It is therefore not surprising that the second most important measure was promoting community health institution construction. When both physicians and patient prefer two-way referral, the key to successful implementation is the convenience and simplicity of the procedure. In addition, constructing a referral platform is central to resolving the problem. Although publicity and communication will affect decision-making to some extent, it is the core interests that will finally determine physician and patient behaviors. Therefore, promoting publicity and communication is the least important aspect.

From the perspective of incentive measures, the ranking of the 12 measures according to importance was as follows: encouraging hospital doctors $>$ software construction $>$ encouraging patients $>$ hardware construction $>$ referral 
(2)

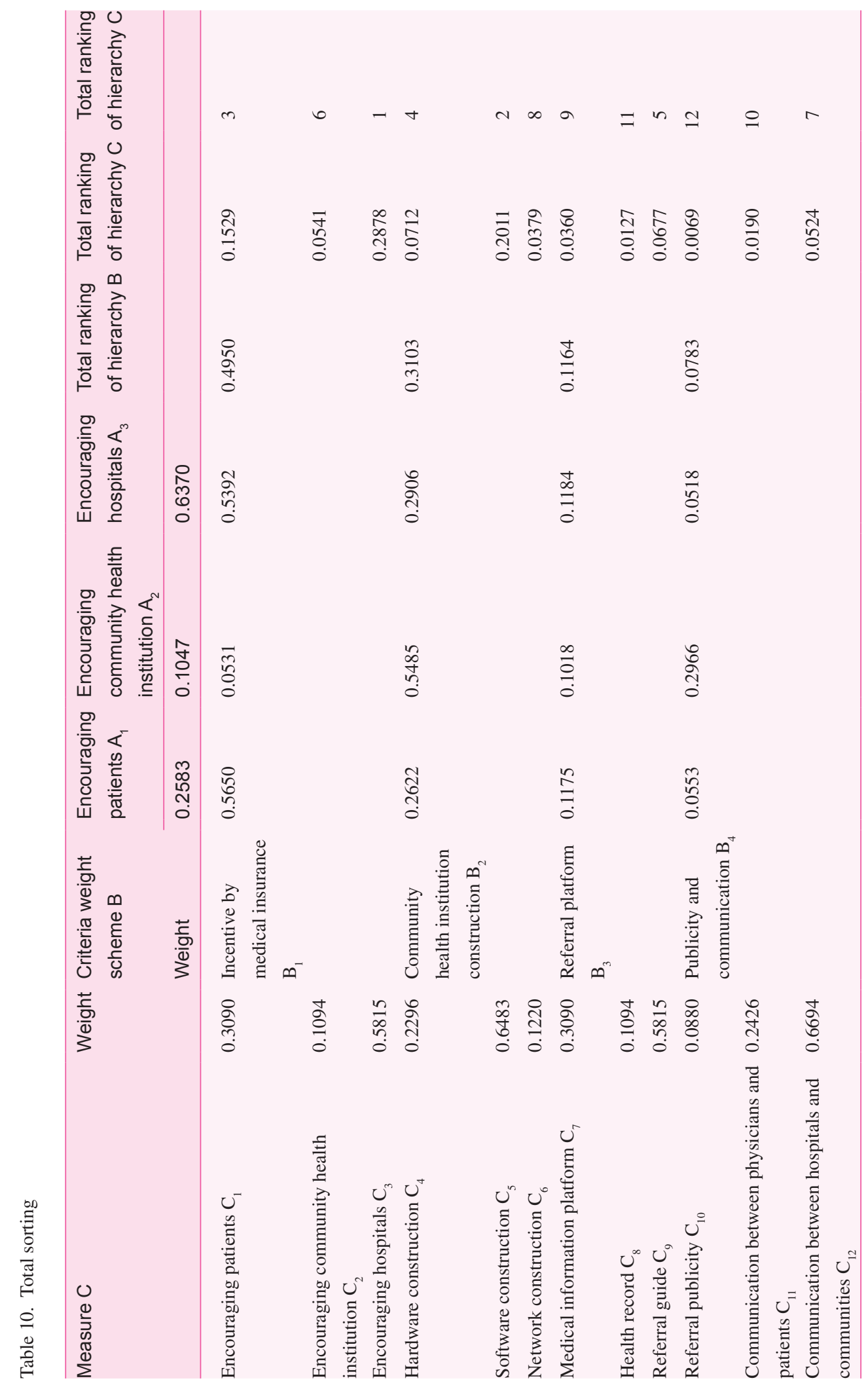


guide $>$ encouraging community health institutions $>$ communication between hospitals and communities $>$ network construction $>$ medical information platform $>$ communication between physicians and patients $>$ health record $>$ referral publicity. Based on this ranking, the top five measures were encouraging the hospital physicians, software improvements in community health institutions, encouraging patients, hardware improvements in community health institutions, and formulating a referral guide. This further demonstrates the fact that the key to successfully implementation of the two-way referral system involves encouraging physicians and patients. Moreover, in order to build the optimal incentive mechanism, the key problem in need of resolution is to implement incentives for hospital physicians and patients to mollify their concerns about the level of clinical treatment in community health institutions, so that two-way referral can be operated conveniently.

In summary, the incentive mechanism for two-way referral involves three aspects: incentive objects, schemes, and measures. Based on the aforementioned research and analysis, hospital physicians should be the first choice of incentive object. The most effective incentive scheme involves implementing incentives based on medical insurance. Finally, the most important incentive measure involves encouraging the hospitals.

\section{Conflict of interest}

The author declares no conflict of interests.

\section{References}

1. The CPC Central Committee and the State Council. The Decision of the CPC Central Committee and the State Council on Health Reform and Development. Beijing, China,1997

2. Zhou R, Liu Z, Fang Y. Current situation and countermeasures of the community two-way referral. J Comm Med 2005;3:32-3.

3. Cheng B, Li W, Su D, Chunliang L, Guangzhen C, Yuansheng L, et al. Investigation of the regional NRCMS twoway referral based on the rural township hospitals and doctors. Chin Gen Pract 2012;15:2564-6.

4. Chen Q. Study on phenomenon of "Dual Referral Zero Case." Chin Gen Pract 2008;11:1734-5.

5. Chen Q, Lei G, Xiao J, Ruiming L. Reason and counter measure analysis of the phenomenon of the hard downward referral of the dual referral. Soft Sci Health 2012;26:675-7.

6. Yang J, Li P, Li Y. Current situation and consideration of the dual referral of the Zhenxin Community Health Service Center in Jiading District, Shanghai Province. Chin Gen Pract 2012;15:2247-9.

7. Xiong M, Gan X. Construction of the 112 dual referral mode: Research on difficulties and countermeasures of the dual referral in China. Chin Health Serv Manag 2012;29:731-3. 